\title{
Kamera Görüntüsü Tabanlı Kömür Tozu Patlayabilirlik Ölçme Sistemi
}

\author{
Abdulkadir ÜRÜNVEREN¹, Buse Melis ÖZYILDIRIM², Mutlu AVCI ${ }^{3}$, \\ Suphi URAL ${ }^{1}$ \\ ${ }^{1}$ Çukurova Üniversitesi, Mühendislik Fakültesi, Maden Mühendisliği Bölümü, Adana \\ ${ }^{2}$ Çukurova Üniversitesi, Mühendislik Fakültesi, Bilgisayar Mühendisliği Bölümü, Adana \\ ${ }^{3}$ Çukurova Üniversitesi, Mühendislik Fakültesi, Biyomedikal Mühendisliği Bölümü, Adana
}

Geliş tarihi: $30.03 .2018 \quad$ Kabul tarihi: 25.12 .2018

\section{Özet}

Bu çalışmada, yeraltında üretim, nakliye ve depolama işleri sırasında biriken kömür tozlarının patlama sınırlarını belirleyerek patlamanın önlenmesi amacıyla serpilecek taş tozu miktarının belirlenmesi için geliştirilen kamera görüntüsü tabanlı sistemle yapılan deneylerden elde edilen sonuçlarla laboratuvarda elde edilen taş tozu-kömür tozu karışımlarının sonuçları karşılaştırılmıştır. Deneylerde Zonguldak/Kozlu Bölgesinden temin edilen kömür tozları kullanılmıştır. Kamera görüntüsü Tabanlı Ölçme Sistemi, deney numunelerindeki taş tozu oranlarını en fazla \%0,026 hata ile tanımlamaktadır.

Anahtar Kelimeler: Kömür tozu, Renk ayrımı, optik yansıma, Patlayabilirlik, Yapay zeka

\section{Camera Image Based Coal Dust Explosibility Measurement System}

\begin{abstract}
In this study, the results obtained from the experiments with the camera image-based system developed for determining the amount of stone dust to determine the explosion limits of the coal dusts accumulated during the underground production, transport and storage works and to prevent explosion were compared with the results of the stone dust-coal dust mixtures obtained in the laboratory. In the experiments, coal dust obtained from Zonguldak/Kozlu Region was used. The camera image Base Measurement System describes the stone dust ratios of the test specimens with an error of $0.026 \%$.
\end{abstract}

Keywords: Coal dust, Color seperation, Optic reflection, Explosibility, Artificial intelligence

*Sorumlu yazar (Corresponding author): Abdulkadir ÜRÜNVEREN, aurunveren@cu.edu.tr 


\section{GíRiș}

Yeraltı kömür ocaklarında üretim, nakliye ve depolama işlemleri sırasında meydana gelen tozlarının patlamaları, daima yeraltı maden işletmeleri için karşılaşılan en önemli tehlikelerden birisi olmuştur. Yeraltı kömür ocakları galeri tabanında, duvarlarında ve tahkimat üstlerinde biriken kömür tozları uygun şartlar oluştuğunda, ocak havasında askıya geçerek patlayabilirler. Kömür tozu patlamaları sonucunda ocak içerisindeki sıcaklıklar, $2000{ }^{\circ} \mathrm{C}$ 'a kadar çıkarken CO gazı konsantrasyonu da \%10'lara kadar çıkabilmektedir [1]. Kömür tozu patlaması sonucunda, yüksek sıcaklık ve/veya zehirli gazlara maruz kalan çalışanların büyük bir çoğunluğu ya hayatlarını kaybetmekte ya da ciddi şekilde yaralanmaktadır. Bu kazaların bazıları şunlardır: 10 Mart 1906 yllında Kuzey Fransa'daki Courriéres madenindeki patlamada 1099 işçi, 1926 yılında Güney Afrika Durnacol'da 125 işçi, 1972 yılında Zimbabwe Wankie'de 427 işçi, 1993 yılında Zonguldak, Kozlu Bölgesi'nde 263 işçi, 2003 yilında Karaman, Ermenek İlçesi'nde 10 işçi, 2010 yllında Balıkesir, Dursunbey İlçesi'nde 17 işçi grizu/kömür tozu patlaması sonucunda hayatını kaybetmiștir [2]. Zonguldak Kozlu bölgesi kömür tozlarının patlama indeksi (KSt) 42-60 arasında olup patlayabilir özellik göstermektedir [3].

Kömür tozu patlamalarının önlenmesi amacıyla 20. yüzyılın başlarından itibaren çeşitli çalışmalar yapılmış olup önceleri patlamaların uçucu madde oranına bağlı olduğu düşünülmüş ancak [4] Avustralya kömürleri üzerine yaptığı çalışmalarda \%8,7'nin altında uçucu madde içeren kömür tozlarının da patlayabildiği ortaya çıkmıştır. Bu çalışma ile kömür tozlarının patlamasını önlemek için yanmayan madde miktarının \%75-85 olması gerektiği belirlenmiştir. Bu nedenle Kömür tozu patlamalarını önlemek üzere, "Şistleme" adı verilen bir yöntemle kömür tozu birikmesi muhtemel yerlere kireçtaşı tozu serpilerek ortamdaki yanmayan madde miktarı \%75-85 oranına kadar yükseltilmektedir. Günümüzdeki uygulamalarda bir miktar değişiklikler görülmesine rağmen bir çok ülke taş tozu konsantrasyon sınırlarını belirlemiştir. ABD Madenlerde İș Sağlığı ve Güvenliği İdaresinin bildirdiğine göre yeraltı kömür ocaklarında, taş tozu oranının giriş havasındaki toplam toz konsantrasyonunun $\% 65$ 'i ve çıkış havasında en az $\% 80$ olması gerektiği ifade edilmektedir [5]. Türkiye'de sinırlayıcı bir mevzuat olmamasina rağmen Çalışma Bakanlığının tavsiye niteliğindeki kararına göre yeraltı kömür ocaklarında taş tozu konsantrasyonunun toplam toz konsantrasyonu içerisindeki payının en az \%65 olması gerektiği belirtilmiş̧ir [6].

Kömür tozu patlamalarını önlemek üzere, "Şistleme" adı verilen bir yöntemle kömür tozu birikmesi muhtemel yerlere kireçtaşı tozu serpilerek ortamdaki kömür tozu konsantrasyonu patlayabilirlik seviyesinin altına düşürülmektedir. Uygulamanın etkinliğini ölçmek üzere gerçekleştirilen geleneksel yöntemde, Şistleme işlemi sonrası, ocak yollarından alınan tozlar laboratuvara gönderilerek $500-530{ }^{\circ} \mathrm{C}$ 'de 4 saat süreyle yakıldıktan sonra geriye kalan kısmının taş tozu oranını temsil ettiği kabul edilmektedir [1]. Laboratuvarda kül analizi ile elde edilen sonuçlar için 4 ile 8 saat arasında bir süre gerekmektedir. Madenlerdeki iş güvenliğinin sağlanması ve kömür tozu patlamalarının önlenmesi bakımından bu süre oldukça uzundur. Yeraltı ocak yollarından alınan toz numunelerinin patlayabilirlik derecelerini hızlı bir şekilde ve yerinde (ocak içerisinde) belirleyebilmek için optik yansıma esasına göre ölçüm yapan, taşınabilir cihazlar geliştirilmiştir [7].

Optik yansıma esasına göre çalışan ilgili sistemler sadece taş tozu uygulamasının başarılı olup olmadığı hakkında bilgi verebilmektedir. Ancak, yöntem toz numunesi içerisindeki taş tozu-kömür tozu oranlarını net bir şekilde veremediği için, uygulamanın devamında ortama atılması gereken taş tozu miktarının ayarlanması ile ilgili herhangi bir bilgi vermemektedir [7].

$\mathrm{Bu}$ çalışmada, maden ocağı içerisinden alınan toz örneklerindeki taş tozu/kömür tozu oranlarının belirlenmesini hızlı bir şekilde mümkün kılan ve kullanıcısını yönlendirerek kömür tozu patlamasının önlenebilmesi için gerekli önlemlerin alınmasında önemli bir rol oynayan, kendisine ait kamera, 1şıklandırma, mikroişlemcili sistem, dokunmatik ekran, kablolu ve kablosuz çevresel haberleşme ve besleme ünitelerinden oluşan, Alev 
Sızdırmaz özelliğine sahip ve kamera görüntüsü tabanlı bir ölçme sistemi tanıtılmaktadır.

\section{MATERYAL VE METOT}

\subsection{Materyal}

$\mathrm{Bu}$ çalışma kapsamında Zonguldak-Kozlu bölgesinden alınan kömür numuneleri kullanılmıştır. Kozlu formasyonu, Zonguldak taşkömürü havzasının işletilebilir nitelikteki kömür damarlarını içeren birimlerinden birisidir. Konglomeralar değişik boyutlarda kuvarsit, magmatik ve metamorfik kayaç çakıllarından oluşmuştur. Kumtaşlarının tane boyutu ise inceden kaba taneliye kadar değişebilmektedir. Birimin yaşı Westfaliyen A'dır. Kömür damarlarının kalınlığ 0,50 metre ile 6 metre arasında değişmektedir. Kömürlerin tabanı genellikle silttaşı kiltaşından oluşan bir istif sunar. Tavanlar ise genellikle kiltaşı, silttaşı olmakla beraber, bazı kömür damarlarının aşındırmalı bir tavanla örtüldüğü gözlenir. İstif; Bartın ve Zonguldak yöresinde $800 \mathrm{~m}$ kalınlık göstermesine karşın, Armutçuk yöresinde 0-300 m kalınlıktadır. Alttaki Alacaağzı formasyonu ile ilişkisi tedrici geçişli izlenmektedir [8].

\subsection{Metot}

$\mathrm{Bu}$ çalışma kapsamında, Optik yansıma esasına göre çalışan sistemlerden farklı olarak kamera ile renk ayrımı yapan bir sistem geliştirilmiştir. $\mathrm{Bu}$ çalışmada ortaya konulan, görüntü işleme ve yapay zekâ tekniklerini barındıran, kendi başına bağımsız olarak çalışan bir sistem olup dünyadaki tüm yeraltı kömür ocaklarında Şistleme uygulamalarını hızlı, güvenilir ve yüksek hassasiyette ölçebilecek adapte edilebilir bir sistemdir. Geliştirilen bu cihaz ve ölçme sistemi için P.BŞV.2017/110 referans numarası ile patent başvurusu yapılmış olup patentlenme işlemleri devam etmektedir.

Böylece kömür tozu patlama riski, cihazın anlık ve hızlı ölçümü sayesinde maden ocağında kömür tozunun yoğun olarak bulunduğu alanlara taş tozunun zamanında ve yeterli miktarda ilavesiyle minimize edilebilecektir.
Mevcut sistemlerin taş tozu-kömür tozu oranı tespiti renk algılayıcılı devrelerin algılayıcı hassasiyeti ile sinırlı durumdadır. Bu algılayıcılar ile elde edilen renk yelpazesi farklı türde kömürler için yeterli tonlama aralığı sağlayamamakta, bu tür çözümler genellikle geliştirildikleri kömür türü ile kısıtlı başarım göstermektedir. Literatürde renk algılayıc1lı sistemlere alternatif kamera tabanlı çözümler de mevcuttur. Ancak, sunulan çözümler genellikle renk algılayıcılı veya kızıl ötesi kamera ile algılama ve analiz yaklaşımlarıdır. Kamera ile renk analiz çalışmaları mevcut olup genellikle gıda ve tekstil sektörlerine yöneliktir $[9,10]$. Fakat bu çalışmada geliştirilen cihazda olduğu gibi bu tipte kamera sistemi ve yapay zekâ ile bütünleşik çalışan bir sistem ilk defa geliştirilmiştir.

Çalışmada sistemin kalibrasyonun tam yapılabilmesi için taş tozu/kömür tozu oranları tarafımızca belirlenen numuneler kullanılmıştır.

\subsubsection{Sistemin Çalışma Prensibi}

Sistem, barındırdı $\breve{1}$ numune hazırlama aparatları, kamera, 1şıklandırma, mikroişlemcili sistem, dokunmatik ekran, çevresel haberleşme ve besleme ünitelerinden oluşan bir yapıda olup, kendi başına çalışır haldedir (Şekil 1).

Kameradan aldığı kömür numunelerinin görüntülerine göre yapay zekâ ve makine öğrenmesi yöntemleri kullanılmış, böylece kömür tozu/taş tozu karışımlarının oranlarını (ağırlıkça \%) tahmin ederek bu karışımların patlayabilirlik dereceleri belirlenmektedir. Ortamdaki metan gazı biliniyorsa, bu değer de, kamera görüntüsü tabanlı kömür tozu patlayabilirlik ölçme sistemine dahil edilir. Böylece kamera görüntüsü tabanlı kömür tozu patlayabilirlik ölçme sistemi, metan gazı konsantrasyonunu da dikkate alarak kömür tozu patlayabilirlik derecesini tayin edebilmektedir. $\mathrm{Bu}$ işlemler için görüntü işleme, sayısal veri işleme ve filtreleme teknikleri ile veri çıkarımı yapılmakta, işlemcisi üzerinde bulunan yapay zekâ yazılımı ile tahminde bulunmaktadır (Şekil 2). 


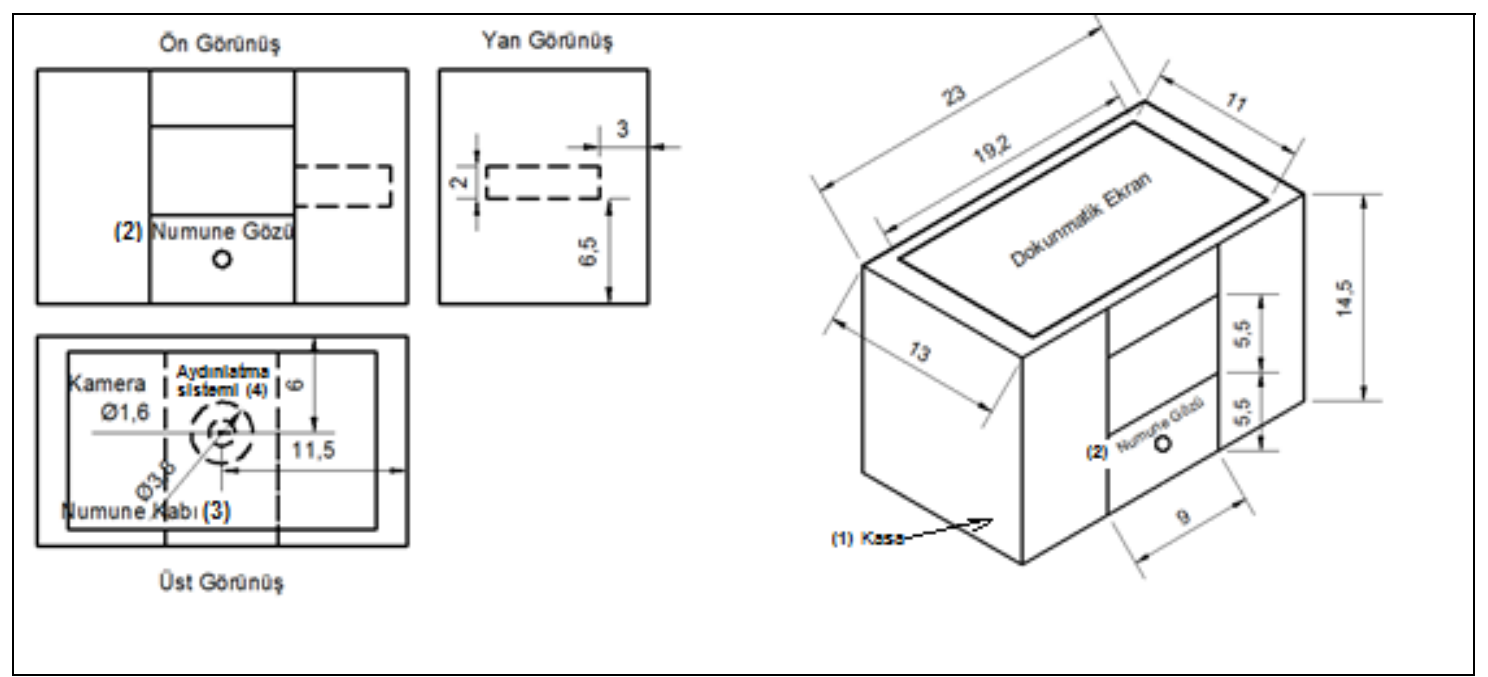

Şekil 1. Çalışma kapsamında geliştirilen hızlı taş tozu-kömür tozu oranı ölçme cihazının genel görünümü ve önemli parçaları

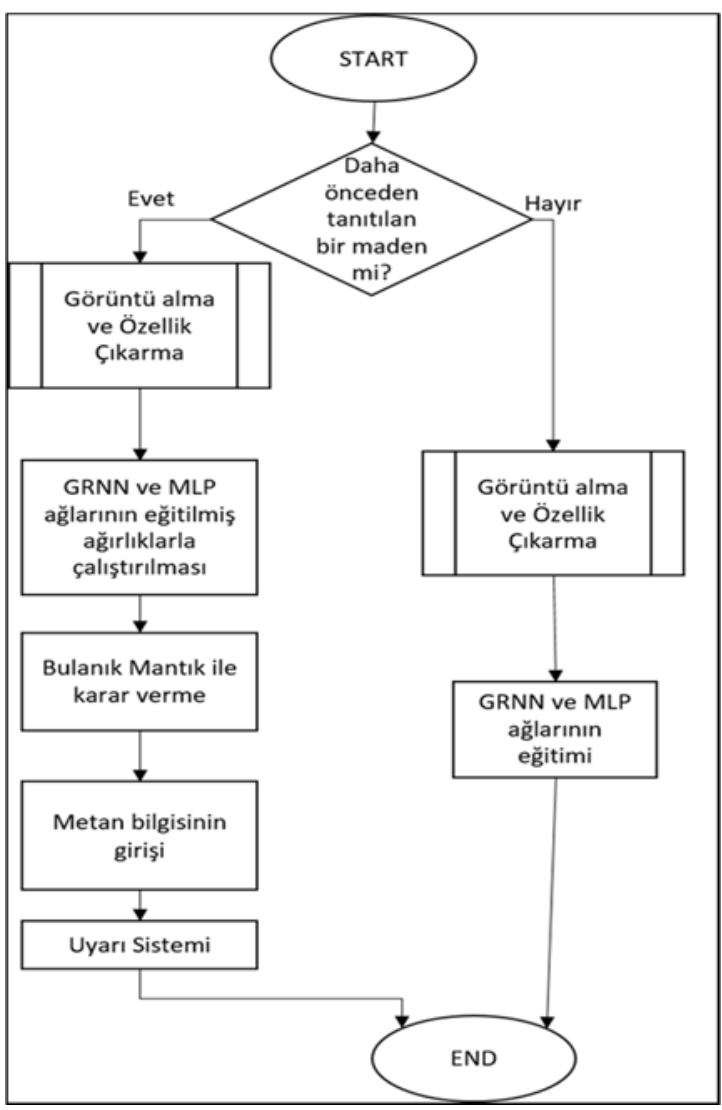

Şekil 2. Kömür tozu/taş tozu tanıma yazılımının akış şeması
Çalışma kapsamında geliştirilen cihaz, içerdiği kamera ile taş tozu-kömür tozu karışımlarına ait görüntülerin uygun ön işleme adımlarının ardından yapay sinir ağına uygulanması sonucu taş tozukömür tozu yüzde miktarlarını (ağırlıkça) tespit etmektedir. Bu cihaz ile ölçülecek taş tozu ve kömür tozu oranları mevcut cihazlara göre daha hassas sonuç vermektedir (ağırlıkça $\pm \% 1$ ).

Sistem üzerinde yürütülecek yapay sinir ağ1 çözümleri güncel ve ileri yapay sinir ağ 1 topolojilerini ve eğitim yöntemlerini içermektedir. Tahmin işleminde GRNN (Genelleştirilmiş Regresyon Yapay Sinir Ağı) ve MLP (Çok Katmanlı Perceptron) Yapay Sinir Ağları kullanılmaktadır. $\mathrm{Bu}$ iki yapı eğiticili öğrenen Yapay Sinir Ağları olup, tahmin problemlerinin çözümünde etkin olarak kullanılmaktadırlar. İki Yapay Sinir Ağının eğitimi, tespit işlemine başlamadan önce, analizi yapılacak olan kömür tozu numunesinin sisteme tanıtılması aşamasında gerçekleştirilmektedir. Eğitim verileri için çalışılacak madenden alınan örneklere aynı işlemler uygulanarak gerekli altı (6) renk tabanlı özellik ve hassas teraziden alınan ağırlık bilgileri kullanılarak yapay sinir ağlarının katsayıları elde edilmektedir. Tek veya çoklu yapay sinir ağlarının bir arada kullanımı ile elde edilen yapay zekâlı uzman sistem sayesinde, hata payı eş işlevli cihazlara göre çok 
daha küçüktür. Kamera görüntüsü tabanlı kömür tozu patlayabilirlik ölçme sistemi, kendi başına çalışabilir ve taşınabilir bir donanım olup üzerinde gerçekleştirilen amaca özel yazılım ile birlikte sistem olarak özgün bir çözümdür.

Geliştirilen sistem ile ölçüm yapılabilmesi için öncelikle yeraltı ocağından alınan kömür tozu numuneler, $355 \mu \mathrm{m}$ elekten geçirilerek kurutulmalıdır. Kurutma işleminin öncelikli amacı kömürün kuru bazdaki renginin ortaya çıkarılmasıdır. Kömürler kuruduğunda gerçek renklerini ortaya koymaktadır. Ayrıca yeraltı kömür ocaklarında şistleme işlemi için kullanılan kireç taşı tozunun 20 Mesh $(355 \mu \mathrm{m})$ 'ten küçük olması istendiğinden kömür tozu boyutunun daha uygun ayrımı için kömür tozları da 355 mikronluk elekten geçirilmektedir. Kömür ocaklarından alınan kömür tozu numunelerinin arazi koşullarında sabit tartıya gelinceye kadar kurutulması işlemi moleküler elek ile yapılır. Alümina silikat kristalleri, moleküler elek olarak da adlandırılmaktadır (Şekil 3).

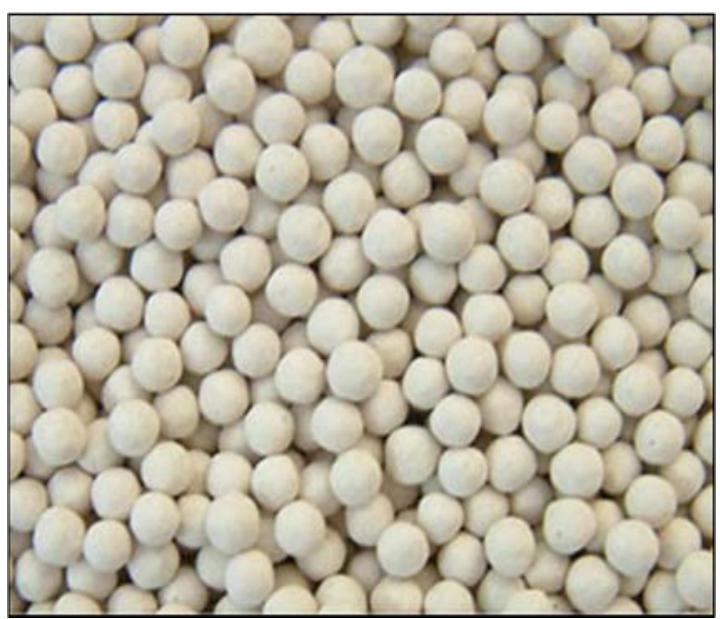

Şekil 3. Moleküler elek granül yapısı

Moleküler elek geniş gözenekli kristal yapıya sahiptir. Bu gözenekler suyu veya başka polar molekülleri adsorblama ve tutma özelliğine sahiptir. $1000 \mathrm{~m}^{2} /$ g'a yakın bir yüzey alanında nem ve diğer akışkanları adsorblayabilir. Kömür numuneleri sabit tartıya, 5 dakika'lık kurutma süresinde, 200 genlik/dakika ve 1/5 oranında kömür tozu-moleküler elek şartlarında getirilir. Kullanılan moleküler elek granüllerin boyutları 8-12 mesh
(1,68-2,38 mm) aralığında olup kurutulan kömür numunesinin bu granüllerden ayrılması için $355 \mu \mathrm{m}$ elekle eleme işlemine tabi tutulur. Böylece kömür tozu numuneleri Kamera görüntüsü tabanlı kömür tozu patlayabilirlik ölçme sisteminde analiz edilmeye hazır hale getirilir. Kömür tozu numunesi hazırlandıktan sonra, cihazın numune gözüne (Şekil 1) yerleştirilir.

Kömür tozu/taş tozu tanıma yazılımının çalıştırılmasıyla birlikte kamera kalibrasyon işlemleri otomatik olarak gerçekleştirilerek 1 şık şiddeti otomatik olarak ayarlanır.

Aydınlatma sisteminin bütün girişleri analogdur. $\mathrm{Bu}$ veriler analogdan sayısala dönüştürücü kullanımı ile sayısallaştırılmaktadır. Kamera ile numunenin RGB (Red-Kırmızı, Green-Yeşil, BlueMavi) renk uzayında görüntüsü alınır. Şekil 4'te alınan görüntüden bir örnek verilmiştir.

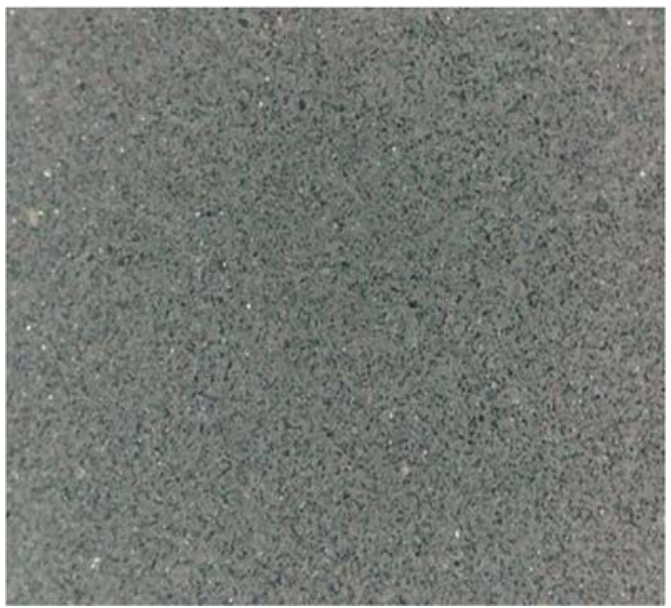

Şekil 4. RGB renk uzayında alınan kömür tozu görüntüsü

Belirlenen alandaki piksel değerlerinin $R, G$ ve $B$ bileşenleri tek tek elde edilip toplamları hesaplanır ve eldeki piksel sayısına bölünerek ortalama değerleri ve varyans değerleri her bileşen için ayrı ayr1 ( $R_{\text {ortalama }}, \mathrm{G}_{\text {ortalama }}, \mathrm{B}_{\text {ortalama, }} \mathrm{R}_{\text {varyans, }}, \mathrm{G}_{\mathrm{vary}}$, $\left.B_{\text {varyans }}\right)$ elde edilir. Ölçüm hassaslığını arttırmak amaciyla RGB uzayından HSL (Hue-Renk, Saturasyon-Doygunluk, Light-Parlaklık) uzayına dönüşüm yapılır. Şekil 5'de HSL uzayına dönüştürülmüş olan örnek görüntü verilmiştir. 


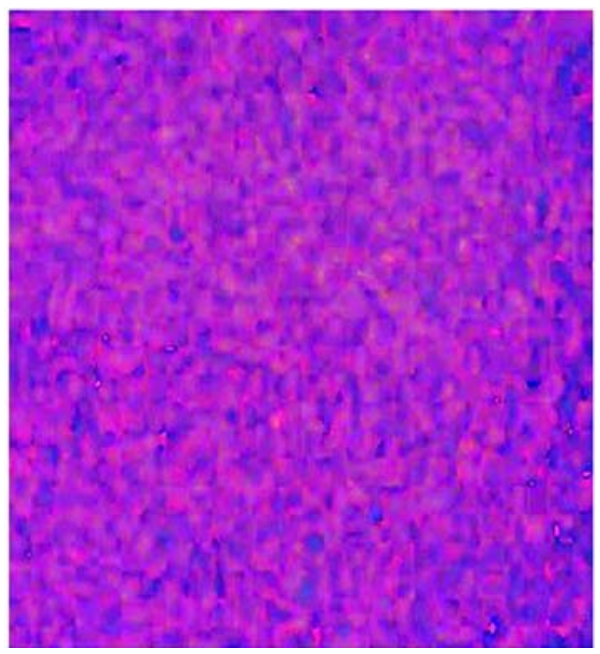

Şekil 5. HSL uzayına dönüştürülmüş olan örnek görüntü
RGB uzayında olduğu gibi, HSL uzayında da her bileşen ayrı ayrı elde edilerek toplanır ve her bileşenin ortalama ve varyans değerleri $\left(\mathrm{H}_{\text {ortalama, }}\right.$ $\mathrm{S}_{\text {ortalama }}, \mathrm{L}_{\text {ortalama}}, \mathrm{H}_{\text {varyans, }} \mathrm{S}_{\text {varyans, }} \mathrm{L}_{\text {varyans }}$ ) elde edilir. Sistem ile alınan ölçümlerden bir tanesi Çizelge 1'de örnek olarak verilmiştir. Görüntülerden elde edilen bu on iki farklı özellik kullanılarak numunedeki taş tozu ve kömür ağırlıkça oranlarına karar verilir. Ayrıca istenirse sisteme hassas terazi eklenerek alınan ağırlık bilgisi de altı (6) farklı özelliğge ek olarak kullanılır. Kömür tozu numunesindeki taş tozu ve kömür ağırlıkça oranlarına altı (6) ve/veya yedi (7) farklı özellik kullanılarak karar verilir. Ağırlık girdisi opsiyonel olup tartı istendiği takdirde aktifleşecektir. Aksi takdirde sadece renk tabanlı özellikler kullanılacaktır.

Çizelge 1. Görüntülerden elde edilen on iki farklı özellik

no Red Green Blue VarRed VarGreen VarBlue Hue Sat Lght VarHue VarSat VarLght
$1,32.1788,35.1902,31.0751,0.331386,0.340198,0.374999,52.3877,19.964,32.9091,8.3275,1.85364,0.348329$
$1,32.5333,35.1913,31.1594,0.27766,0.356865,0.399243,52.1797,17.7288,33.2602,12.0566,2.23685,0.350947$
$1,32.2818,35.29,31.2297,0.263743,0.345225,0.414949,48.3854,20.878,32.9392,14.9939,1.80605,0.358761$
$1,32.6727,35.2638,31.3235,0.277047,0.379853,0.377587,44.7356,19.2919,33.2143,13.5676,2.55718,0.289863$
$1,32.5192,35.3183,31.3857,0.363842,0.352691,0.383711,55.1461,18.1333,33.3092,14.1114,2.48725,0.383217$

\section{ARAŞTIRMA BULGULARI}

\subsection{Kısa Analiz, Toplam Kükürt ve Alt Isıl Değer Analizleri}

Zonguldak/Kozlu bölgesinden alınan numunelerin kimyasal içerikleri XRF cihazıyla bulunmuştur. Bölgeden alınan yantaşa ait kimyasal analiz sonuçları Çizelge 2'de verilmiştir. Kömür numunelerin kül, nem, uçucu madde ve sabit karbon özellikleri ile kükürt ve kalori değerleri belirlenerek kısa analiz, toplam kükürt ve alt ısıl değer analiz sonuçları Çizelge 3 'te verilmiştir. Yeraltı kömür ocağında kömür tozu patlamalarının engellenmesi için serpilen kireç taşı tozunun \%43,07'lik bir kızdırma kaybı ve \%0,5'lik bir silis içeriği vardır.

Çizelge 2. Zonguldak/Kozlu bölgesinden alınan yantaşa ait kimyasal analiz sonucu (\%)

\begin{tabular}{|c|c|c|c|c|c|}
\hline $\mathrm{TiO}_{2}$ & $\mathrm{Al}_{2} \mathrm{O}_{3}$ & $\mathrm{SiO}_{2}$ & $\mathrm{~K}_{2} \mathrm{O}$ & $\mathrm{MoO}_{3}$ & $\mathrm{Fe}_{2} \mathrm{O}_{3}$ \\
\hline 1,70 & 26,2 & 61,65 & 4,68 & 0,49 & 5,28 \\
\hline
\end{tabular}

Çizelge 3. Zonguldak/Kozlu numunelerinin kısa analiz, toplam kükürt ve alt ısıl değer analiz sonuçları

\begin{tabular}{|l|c|c|}
\hline Analiz (havada kuru) & $\begin{array}{c}\text { Kozlu } \\
\text { (Kömür) }\end{array}$ & $\begin{array}{c}\text { Kozlu } \\
\text { (Yantaş) }\end{array}$ \\
\hline Sabit karbon (ă̆. \%) & 65,38 & 1,87 \\
\hline Kül (ağ. \%) & 3,79 & 89,63 \\
\hline Uçucu madde (ağ. \%) & 29,29 & 6,86 \\
\hline Nem (ă̆. \%) & 1,54 & 1,64 \\
\hline Kükürt (ağ. \% ) & 0,55 & 0,19 \\
\hline Alt Isıl Değer (Kcal/kg) & 6620 & - \\
\hline
\end{tabular}

\subsection{Kamera Görüntüsü Tabanlı Sistem ile Yapılan Ölçümler}

Ölçme Sistemi ile renk ayrımı ölçümleri yapılarak taş tozu-kömür tozu oranları belirlenmeye çalışılmıştır. Bu ölçümlerde taş tozu oranı önceden belirlenmiş olan numuneler kullanılmıştır. Ayrıca çalışma sahasından getirilen yantaştan elde edilen tozlar kullanılmıştır. Yapılan ölçümler sonucunda elde edilen değerler Çizelge 4 ve Çizelge 5'te verilmiştir. 
Çizelge 4. Sistem ile yapılan renk ölçüm değerleri

\begin{tabular}{|l|c|c|c|c|c|c|}
\hline & \multicolumn{7}{|c|}{ RGB Sistemi } \\
\hline $\begin{array}{l}\text { Taş Tozu } \\
\text { Oran1 (\%) }\end{array}$ & Red & Green & Blue & $\begin{array}{c}\text { Var } \\
\text { red }\end{array}$ & $\begin{array}{c}\text { Var } \\
\text { green }\end{array}$ & $\begin{array}{c}\text { Var } \\
\text { blue }\end{array}$ \\
\hline 100 & 76,61 & 78,81 & 75,59 & 9,00 & 5,43 & 6,89 \\
\hline 97,5 & 63,37 & 66,72 & 62,23 & 14,44 & 7,67 & 9,63 \\
\hline 95 & 42,54 & 45,89 & 41,58 & 12,23 & 4,69 & 6,42 \\
\hline 92,5 & 24,45 & 27,86 & 24,24 & 9,24 & 6,43 & 6,95 \\
\hline 90 & 21,16 & 25,63 & 21,25 & 7,26 & 3,24 & 3,31 \\
\hline 87,5 & 16,50 & 20,64 & 16,72 & 5,59 & 5,20 & 4,27 \\
\hline 85 & 11,69 & 14,72 & 11,30 & 7,30 & 5,55 & 5,09 \\
\hline 82,5 & 9,52 & 13,12 & 9,32 & 3,14 & 5,57 & 3,84 \\
\hline 80 & 8,55 & 13,24 & 9,43 & 3,96 & 2,36 & 2,15 \\
\hline 77,5 & 4,75 & 9,32 & 4,98 & 3,32 & 2,05 & 1,58 \\
\hline 75 & 2,91 & 7,51 & 3,13 & 2,30 & 2,08 & 1,40 \\
\hline 72,5 & 1,66 & 5,27 & 1,72 & 0,93 & 3,63 & 0,98 \\
\hline 70 & 0,95 & 3,52 & 0,88 & 0,38 & 1,91 & 0,23 \\
\hline 67,5 & 1,64 & 3,11 & 1,21 & 0,46 & 0,66 & 0,16 \\
\hline 65 & 0,73 & 3,39 & 0,70 & 0,22 & 2,76 & 0,19 \\
\hline
\end{tabular}

Çizelge 5. Sistem ile yapılan doygunluk ölçüm değerleri

\begin{tabular}{|c|c|c|c|c|c|c|}
\hline & \multicolumn{6}{|c|}{ HSL Sistemi } \\
\hline $\begin{array}{l}\text { Taş Tozu } \\
\text { Oranı }(\%)\end{array}$ & Hue & Sat & Light & $\begin{array}{l}\text { Var } \\
\text { hue }\end{array}$ & $\begin{array}{l}\text { Var } \\
\text { sat }\end{array}$ & $\begin{array}{l}\text { Var } \\
\text { light }\end{array}$ \\
\hline 100 & 42,35 & 6,04 & 76,57 & 15,22 & 0,60 & 7,08 \\
\hline 97,5 & 38,45 & 9,88 & 64,18 & 33,33 & 1,71 & 9,89 \\
\hline 95 & 45,42 & 14,88 & 43,66 & 24,86 & 4,93 & 6,86 \\
\hline 92,5 & 46,09 & 23,07 & 25,72 & 24,80 & 17,52 & 7,09 \\
\hline 90 & 48,71 & 30,01 & 23,15 & 28,80 & 40,46 & 3,74 \\
\hline 87,5 & 50,85 & 41,30 & 18,06 & 26,55 & 89,23 & 4,50 \\
\hline 85 & 45,93 & 46,97 & 13,09 & 33,85 & 138,60 & 5,72 \\
\hline 82,5 & 40,36 & 57,35 & 11,27 & 32,57 & 103,02 & 3,97 \\
\hline 80 & 48,99 & 78,47 & 10,64 & 21,97 & 226,78 & 2,22 \\
\hline 77,5 & 43,31 & 116,86 & 6,75 & 25,83 & 318,00 & 1,69 \\
\hline 75 & 45,47 & 144,32 & 4,87 & 13,73 & 559,36 & 1,46 \\
\hline 72,5 & 40,72 & 139,84 & 3,31 & 29,94 & 250,93 & 1,74 \\
\hline 70 & 31,98 & 124,92 & 2,09 & 57,67 & 636,18 & 0,72 \\
\hline 67,5 & 26,97 & 102,69 & 2,21 & 48,92 & 405,22 & 0,31 \\
\hline 65 & 31,55 & 127,78 & 1,97 & 72,04 & 1051,05 & 0,93 \\
\hline
\end{tabular}




\subsection{Sistem Ölçüm Sonuçlarının elde edilmiştir. Bu numuneler geliştirilen sistemle Değerlendirilmesi ölçülerek gerçek değerle karşılaştırılmıştır. Her bir numune için beş farklı ölçüm alınmış olup en büyük \\ Kömür tozu- taş tozu numuneleri hassas terazi yardımıyla belli oranlarda karıştırılarak karışımlar hatayı veren okumanın hata oranı hesaplanarak sonuçlar Çizelge 6 ve Şekil 6'da verilmiştir.}

Çizelge 6. Kamera Görüntüsü Tabanlı sistem ile yapılan ölçüm sonuçları ve gerçek değer sonuçları

\begin{tabular}{|c|c|c|c|}
\hline $\begin{array}{l}\text { Numune içindeki Taş } \\
\text { Tozu (\%) }\end{array}$ & $\begin{array}{r}\text { Sistemin Ölçüm } \\
\text { Değeri }\end{array}$ & Fark $( \pm)$ & Hata Oran $1(\%)$ \\
\hline 100,0000 & 100,0000 & 0 & 0 \\
\hline 97,5000 & 97,5000 & 0 & 0 \\
\hline 95,0000 & 95,0000 & 0 & 0 \\
\hline 92,5000 & 92,5000 & 0 & 0 \\
\hline Yantaş & 90,0000 & 0 & 0 \\
\hline 87,5000 & 87,5000 & 0 & 0 \\
\hline 85,0000 & 85,0000 & 0 & 0 \\
\hline 82,5000 & 82,5000 & 0 & 0 \\
\hline 80,0000 & 80,0000 & 0 & 0 \\
\hline 77,5000 & 77,5000 & 0 & 0 \\
\hline 75,0000 & 75,0000 & 0 & 0 \\
\hline 72,5000 & 72,5000 & 0 & 0 \\
\hline 70,0000 & 69,9936 & 0,00099972 & 0,099971961 \\
\hline 67,5000 & 67,4878 & 0,000348563 & 0,034856329 \\
\hline 65,0000 & 65,2413 & $-0,003712021$ & $-0,371202054$ \\
\hline 62,5000 & 62,4931 & 0,000111194 & 0,011119375 \\
\hline 60,0000 & 60,0000 & $-5,68579 \mathrm{E}-07$ & $-5,68579 \mathrm{E}-05$ \\
\hline 57,5000 & 57,4858 & 0,001067238 & 0,106723804 \\
\hline 55,0000 & 55,0000 & $-6,59594 \mathrm{E}-09$ & $-6,59594 \mathrm{E}-07$ \\
\hline 52,5000 & 52,5000 & $-0,001057923$ & $-0,105792287$ \\
\hline 50,0000 & 50,0000 & $-2,62921 \mathrm{E}-11$ & $-2,62921 \mathrm{E}-09$ \\
\hline 47,5000 & 47,5000 & $6,61126 \mathrm{E}-07$ & $6,61126 \mathrm{E}-05$ \\
\hline 45,0000 & 45,0390 & $-0,000867442$ & $-0,086744245$ \\
\hline 42,5000 & 42,1832 & 0,007454587 & 0,745458725 \\
\hline 40,0000 & 40,0066 & $-0,000165151$ & $-0,016515147$ \\
\hline
\end{tabular}




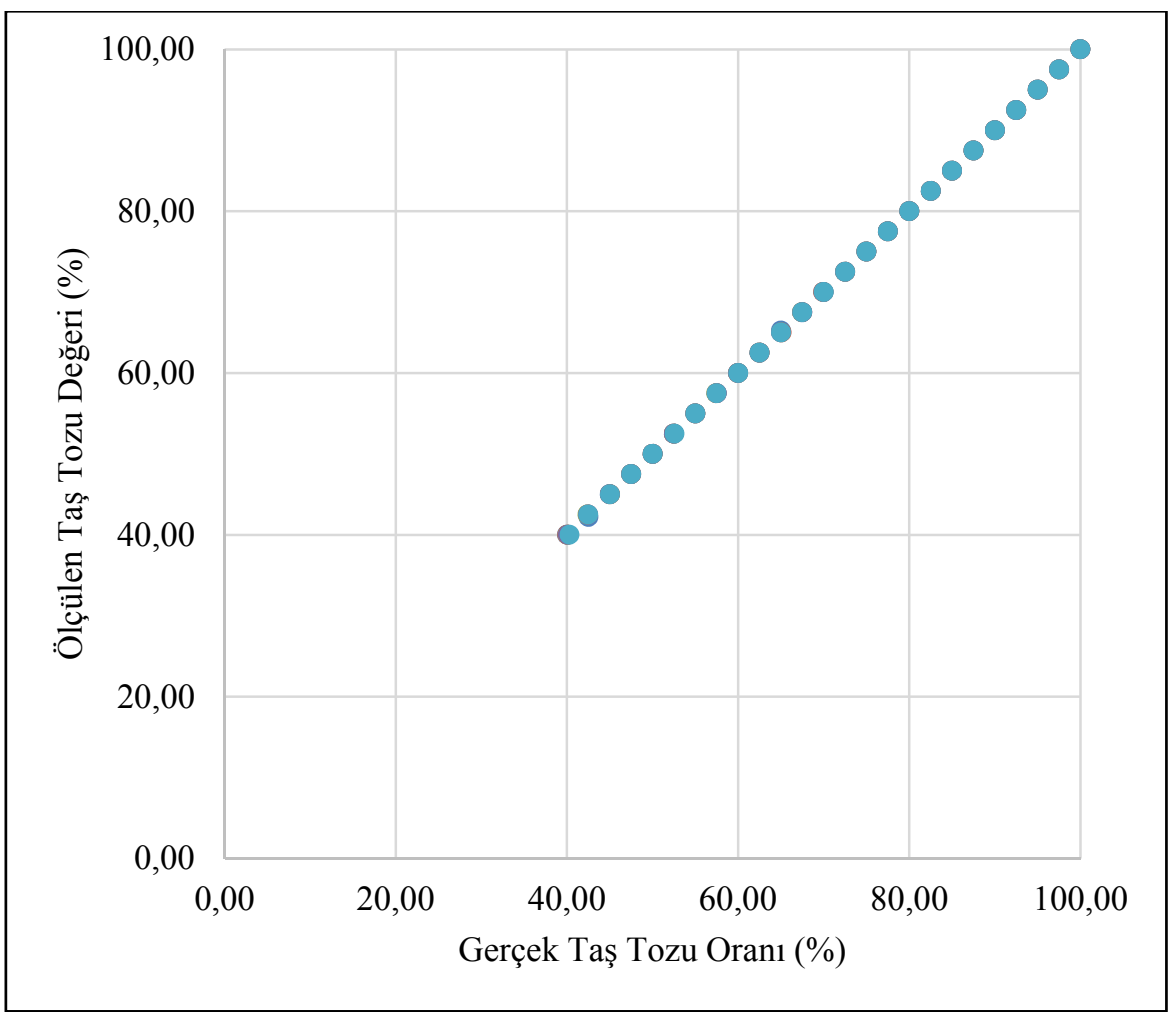

Şekil 6. Gerçek taş tozu oranı ile sistemin ölçtüğü değerlerin karşılaştırılması

\section{SONUÇLAR}

$\mathrm{Bu}$ çalışma kapsamında aşağıdaki sonuçlar elde edilmiştir:

- Kömür tozu patlamalarının engellenmesi amacıyla yeraltı kömür ocaklarında taş tozu serpilmesi uygulaması yaygın olarak yapılmaktadır. Zonguldak kömürleri için de bu oranın en az \%65 olacak şekilde uygulanmaktadır. Şistleme uygulaması etkin bir şekilde uygulanmadığı taktirde kömür tozlarının patlama tehlikesi bulunmaktadır. $\mathrm{Bu}$ çalışmada taş tozu/kömür tozu karışımının içerisindeki taş tozu oranının hızlı ve doğru bir şekilde belirlenebilmesi için bir sistem geliştirilmiştir. Böylece ocaktaki kömür tozlarının içindeki patlamayı engelleyen taş tozu miktarını, uçucu madde, kül analizi ve benzeri analizleri yapmaya gerek kalmadan hızlı ve doğru bir şekilde ölçebilen optik yansıma esasına dayalı bir sistem geliştirilmiştir.
- Kamera görüntüsü Tabanlı Ölçme Sistemi, yeraltı maden ocaklarında biriken kömür tozlarının patlayabilirlik seviyesini numunenin alındığ 1 yerde ve 2 dakika içerisinde ölçebilmektedir.

- Sistem özelliği; kömür tozu numunesinin kamera görüntüsünden elde edilen renk bileşenlerine ve/veya ağırlığına bağlı olarak kömür tozu numunesinin patlayabilirlik derecesini belirlemekte ve ölçülen sonuca göre kullanıcısını yönlendirmektedir.

- Kamera görüntüsü Tabanlı Ölçme Cihazı kömür tozlarının patlayabilirlik seviyesini kamera görüntüsünün renk dağılımına bağlı olarak ölçmekte ve kullanıcısını yönlendirmektedir.

- Toz patlayabilirlik ölçümlerini yaklaşık $\pm \% 0,26$ 'lık bir hata payı ile değerlendirmektedir.

- Optik yansıma esasına göre çalışan cihazı koyu renkli yantaş ve arakesme tabakalarını doğru bir şekilde tanımlayamamaktadır. 
- Kamera görüntüsü Tabanlı Ölçme Cihazı, koyu renkli yantaş ve arakesme tabakalarını doğru bir şekilde tanımlamaktadır.

\section{TEŞEKKÜR}

Yazarlar, Türkiye Taşkömürü İşletmeleri Genel Müdürlüğü'ne sağladıkları teknik destek ve Çukurova Üniversitesi Araştırma Fonu'na (FPT2017-8040; FBA-2017-9002) sağladıkları finansal destekler için teşekkür ederler.

\section{KAYNAKLAR}

1. Ellis, C., 1999. MDG 3006 MRT 5: Guidelines for Coal Dust Explosions Prevention and Suppression, Draft. New South Wales, Australia: Mineral Resources.

2. Madencilik, T., 2014. Dünyanın En Büyük 10 Kömür Madeni Kazası (in Turkish). Madencilik Türkiye, 102-103.

3. Saltoğlu, S., 1971. Zonguldak Havzası Kömür Tozlarının Patlama Karakteristiklerinin Tesbiti ve Kömür Tozu Patlamalarının Taş Tozu ile Önlenmesi Üzerine Yapılan Etüd. EKİ yayını, No: 31.

4. Humphreys, D., O’Beirne, T., 2000. Stone dust Requirements and Options. Australian Coal Association Research Program Project C8011 Final Report to ACARP, Brisbane, Australia.

5. MSHA, 1988. Code of federal regulations (Parts 1-199) [online]. Available at http://www.msha.gov/regdata/msha/75.0htm. The Office of the Federal Register, National Archives and Records Administration.

6. ÇSGB, 2009. Yeraltı Ve Yerüstü Maden İşletmelerinde İş Sağlığı Ve Güvenliği Rehberi, ÇSGB İş Teftiş Kurulu Başkanlığı Yayını, Y. No: 43. Ankara.

7. K1z1l, M.S., Peterson, J., English, W., 2001. The Effect of Coal Particle Size on Colorimetric Analysis of Roadway Dust. Journal of Loss Prevention in the Process Industries. 14, 387-394.

8. Yergök, A.F., Ünal, A., İplikçi, Ü., Karabalık, N., Keskin, İ., Mengi, H., Umut, M., Armağan, F., Erdoğan, K., Kaymakçı, H., Çetinkaya, A.,
1987. Batı Karadeniz Bölgesi Jeolojisi. MTA Rapor No: 8273, 237.

9. Demirbaş, H.Y., Dursun, İ., 2007. Buğday Tanelerinin Bazı Fiziksel Özelliklerinin Görüntü İşleme Tekniğiyle Belirlenmesi. Tarım Bilimleri Dergisi, 13(3), 176-185.

10. Çelik, H.İ., Dülger, L.C., Topalbekiroğlu, M., 2012. Görüntü İşleme Teknikleri Kullanarak Kumaş Hatalarının Belirlenmesi. Tekstil Teknolojileri Elektronik Dergisi, 6, 22-39. 